\title{
Do Animals Feel Pain in a Morally Relevant Sense?
}

\section{Calum Miller ${ }^{1}$}

Received: 25 February 2020 /Revised: 28 July 2020 / Accepted: 1 August 2020 /

Published online: 13 October 2020

(C) The Author(s) 2020

\begin{abstract}
The thesis that animals feel a morally relevant kind of pain is an incredibly popular one, but explaining the evidence for this belief is surprisingly challenging. Michael Murray has defended neo-Cartesianism, the view that animals may lack the ability to feel pain in a morally relevant sense. In this paper, I present the reasons for doubting that animals feel morally relevant pain. I then respond to critics of Murray's position, arguing that the evidence proposed more recently is still largely unpersuasive. I end by considering the implications for moral discourse and praxis.
\end{abstract}

Keywords Pain · Qualia $\cdot$ Pain behaviour $\cdot$ Animal consciousness $\cdot$ Consciousness

\section{Introduction}

It seems obvious to most people that animals feel pain. The almost unanimous response to scepticism - that dogs yelp when kicked - suggests that there is some very common-sense, universal intuition at stake here. But intuitions - especially 'obvious' ones - ought to be scrutinised. I hope to demonstrate that this particular intuition is surprisingly difficult to substantiate, and that those of us (myself included) who think that animals do feel morally relevant pain at least ought to have more humility about the quality of our evidence. At the very least, sceptics about animal pain should not be dismissed instantly. In this essay, I defend such sceptics - in particular, Michael Murray's defence of neo-Cartesianism ${ }^{1}$ from a variety of objections levelled against their position. My view is not that animals do not feel pain. It is that most of the reasons usually given for thinking that they do are not good ones. This presents a hitherto underappreciated epistemological puzzle for those of us who think that animals do feel pain.

${ }^{1}$ Murray (2008).

Calum Miller

c.miller@oxon.org

1 St Benet's Hall, University of Oxford, Oxford, UK 
To help soften my reader up to my thesis, consider a thesis equally obvious to the animal pain thesis - that not all kinds of biological life feel pain. Most people do not think that bacteria or simple multicellular organisms are conscious. At the very least, it is unclear where pain, or any consciousness at all, kicks in, evolutionarily speaking. ${ }^{2}$ This fact is sufficient to demonstrate that the question of which organisms feel pain is a serious and rightly controversial one. Even if we are prepared to accept our intuitions that bacteria do not feel pain and that chimpanzees do, there remains an awful lot of work to be done in the middle ground.

\section{Pain Behaviour}

Rather than claiming a trivial victory on the middle ground, however, I aim to demonstrate that even in the case of higher non-human animals, the arguments supporting the thesis that animals feel morally relevant pain turn out to be surprisingly weak or inconclusive.

By far the most common and obvious of these supporting arguments is that animals exhibit "pain behaviour" - they nurse wounds, yelp when kicked, retract from "painful" stimuli and avoid "painful"-looking objects or creatures. But clearly it is possible that they do all this without actually feeling pain; indeed, we intuit that many forms of life exhibit some kind of "pain behaviour" without feeling pain. Bacteria, for example, retract from noxious substances, but very few people infer that they feel pain when they come into contact with them.

Indeed, whether or not bacteria feel pain ought to be a serious and controversial question for those whose credulity is bought by pain behaviour alone. If avoidance of noxious stimuli is good enough evidence for the view that cats feel pain, why is it not good enough evidence for the view that bacteria feel pain? This kind of view, steering towards panpsychism, is obviously an unpopular one ${ }^{3}$ : but it is hard to see why, if pain behaviour is really such a convincing index of pain qualia. So there is no strictly logical inference to be made solely from pain behaviour.

Might pain behaviour nevertheless provide evidence for the thesis that animals feel pain? Again, this is far from obvious. According to relatively uncontroversial principles of confirmation theory, evidence for a hypothesis is an observation which would be more likely given the hypothesis than otherwise. But, given evolution, we would expect pain behaviour even if animals didn't have a conscious experience of pain. To see why, we must consider why pain behaviour arises in the first place. Suppose, for the sake of argument, that actual pain explains pain behaviour adequately (as it happens, this is not true: we know, for example, that some pain reflexes are mediated without, or before, a conscious experience of pain). Would pain behaviour be less likely, or unexplained, if there were no such conscious experiences? It does not seem that way. For, given evolution, we would expect all these pain behaviours to exist even if no one felt any pain. This is because evolution selects for those organisms better adapted to surviving and reproducing - and pain behaviour enables organisms to survive and reproduce, by keeping them safe from danger. Just as bacteria evolved to retract from noxious substances, so animals evolved to do the same, in their respective macroscopic ways.

\footnotetext{
$\overline{2}$ A standard 'educated guess' puts the dividing line between vertebrates and invertebrates (Francescotti 2013).

${ }^{3}$ Though increasingly popular.
} 
An animal with an unconscious pain withdrawal reflex is less likely to be harmed by dangerous substances, and an animal which nurses wounds is less likely to die from them, promoting the survival of the species. But then pain behaviour seems equally likely, given evolution, whether or not they actually feel pain.

In probabilistic terms, this is a relation known as "screening off." A "screens off" B from $\mathrm{C}$ if the probability of $\mathrm{B}$ given $\mathrm{A}$ and $\mathrm{C}$ is equal to the probability of $\mathrm{B}$ given $\mathrm{A}$. That is, conditionalising on $\mathrm{A}$ renders $\mathrm{B}$ and $\mathrm{C}$ effectively independent. The implication is that, if $\mathrm{A}$ is known, the knowledge of $\mathrm{C}$ does not constitute evidence for $\mathrm{B}$, and the knowledge of $\mathrm{B}$ does not constitute evidence for $\mathrm{C}$. In the case of animal pain, our knowledge of evolution screens off the propositional knowledge regarding pain behaviour from the proposition that animals feel pain. It follows that the observation of pain behaviour, in light of evolution, does not constitute any evidence for the view that animals feel pain. If this is the case, then it may even be argued that the animal pain thesis is an unnecessary auxiliary thesis which should be rejected by Occam's razor.

The deceptive power of pain behaviour might be made plainer by considering known instances where pain behaviour initially seemed to indicate pain, only for us to later find out that there was not plausibly any conscious experience of pain leading to the behaviour. I have already alluded to such an instance in the case of the pain withdrawal reflex - when observing a human withdraw their hand from a hot surface, we intuitively judge that the human must have felt pain. But reflection on the timing of such scenarios makes it very implausible that conscious pain led the hand to withdraw; indeed, more rigorous studies have confirmed that the pain behaviour is initiated before any conscious experience. ${ }^{4}$ Similarly, Grau et al. have demonstrated that much of the pain behaviour of rats, while seeming to be mediated by conscious experience of pain, can be explained by complex patterns in the spinal cord alone. For example, rats still have paw withdrawal and tail-flick reflexes even when spinalized at birth. Moreover, more complex trained responses, like keeping a paw up in the air to avoid shock, can also be learned in spinalized rats. ${ }^{5}$ So we know that not all apparent pain behaviour is mediated by conscious experiences of pain. It is therefore an open question whether any pain behaviour is mediated this way.

The fact that we would expect apparent pain behaviour given evolution means that pain behaviour constitutes very weak evidence, at best, for the thesis that animals consciously feel pain. The fact that we know of instances where our intuitive positing of conscious pain is incorrect gives us further reason to be sceptical.

\section{Morally Relevant Kinds of Pain}

The perceptive reader will note the "morally relevant sense" clause in my title. This may seem perplexing at first - could there be a kind of pain which isn't morally relevant? Indeed, the obviousness of the moral significance of pain has been the impetus for very popular utilitarian approaches to ethics.

But recent developments in neuroscience show that there can indeed be kinds of pain which are not necessarily morally problematic. It is now believed that there are at least

\footnotetext{
${ }^{4}$ Libet (1993).

${ }^{5}$ Grau and Joynes (2001).
} 
two quite different pain processing neural axes. ${ }^{6}$ The first of these is the discriminatory pathway, transmitting signals through the ventroposterolateral nucleus of the thalamus and on to somatosensory cortex. The second is the affective pathway, traditionally thought to run through the intralaminar nuclei of the thalamus to anterior cingulate and prefrontal cortex. The discriminatory pathway relays information regarding the site and modality of sensory input, while the affective pathway mediates the feeling of "badness".

This distinction can plausibly be seen as exposing a kind of pain which is not morally relevant. Consider pain asymbolia, a condition where patients can report that they are in pain along with location and intensity, ${ }^{7}$ but where they do not recognise the unpleasantness of it, and are not bothered by it. This most frequently occurs as the result of iatrogenic interventions (e.g., cingulotomy or lobotomy) or from lesions affecting the same parts of the brain. Some reflexive avoidance is retained in such patients, but they typically claim not to be bothered by, or afraid of, the pain. It is certainly not obvious that it would be wrong to knowingly cause this kind of pain to someone, since there is no feeling of unpleasantness associated with it.

Perhaps, then, negative affect is required for a morally relevant kind of pain. Might there be other necessary components - that the pain is "owned" by a person and attributed to themselves, for example? What if a patient attributed their pain to someone else, or to no one in particular? Perhaps a clear self of self-identity and self-attribution of sensory experiences is necessary. While this is difficult for physiologically typical individuals to imagine, there are hints at the possibility from certain other disorders. Somatoparaphrenia is a disorder arising predominantly from parietal cortex lesions, where patients deny ownership of a limb or a whole side of their body, usually (if not always) in conjunction with unilateral neglect. Dissociative personality disorder and out-of-body experiences are well-known, though controversial. Even split-brain patients seem to be more peculiar than originally thought: Ramachandran presents one patient whose left hemisphere is an atheist but whose right hemisphere is a theist. ${ }^{8}$ This raises all sorts of questions about identity, but the one which concerns us here is whether it is possible for some people (and, most relevantly, animals) to feel pain without attributing it to themselves. The question that then arises is whether this kind of pain is still morally relevant. The suggestion that morally relevant pain requires the pain to be "owned" by a particular person in this sense ought to be taken seriously - it cannot simply be assumed that animals have a sufficiently complex sense of selfidentity for their pain to be morally relevant.

A final possible requirement for morally relevant pain might be the continuity of consciousness - in the sense that painful experiences must be remembered or must otherwise affect subsequent conscious life. Murray gives the example of an anaesthetic agent with the ability to keep a patient conscious during a procedure, while erasing their memory. Suppose this was administered during an operation, along with a paralysing agent. Patients would presumably feel pain during the operation, but would have no recollection of it once the operation was over. Is there much of a moral difference

\footnotetext{
${ }^{6}$ This is a vast oversimplification, as we shall see.

${ }^{7}$ Note that since the patients can also report intensity, they do seem to be experiencing something that can be identified as 'pain' rather than just ordinary tactile sensation. Sollereder (2016) offers a nice illustrative example of a patient who described the pain as still 'agonizing' but claimed not to be bothered at all.

${ }^{8}$ Ramachandran (2006).
} 
between using this combination of drugs and using a normal anaesthetic? Certainly, if one was told in retrospect of an operation that this had been done to them, it would not be clear that they should feel hard done by. So it is at least plausible that a relevant kind of continuity is necessary here. And it is clearly up for debate the extent to which animals have continuity of consciousness and continuity of 'what matters'.

These conditions on morally relevant pain are all highly debatable, and it is beyond the scope of this paper to argue that any of these features are necessary conditions. It is also worth clarifying that I am not claiming that animals plausibly have pain asymbolia, or somatoparaphrenia, or any closely-related conditions. The point is rather that serious discussion can be had both over whether these are required for morally relevant pain, and over whether animals have all these features in addition to simple nociceptive mechanisms (and, of course, whether they are conscious at all - which is not a trivial point, given how little we know about what causes consciousness ${ }^{10}$ ). Our evidence that animals have nociception is, of course, perfectly good. But what is our evidence that animals have the features I have described here? What is our evidence that animals have qualia at all? If the arguments from the first section are taken seriously and applied to these further questions, it is far from clear that we have decisive evidence that animals have all of these features.

\section{Anatomical Arguments}

The final remaining argument for the animal pain thesis is the similarity of human and animal central nervous systems. Earlier, I questioned whether animals - assuming they have qualia at all - have the relevant affective dimension of pain. I pointed to pain asymbolia as an example of a condition in humans where this affective component is absent. Although, as we shall see, the neuroanatomical correlates of pain asymbolia are more complex than typically thought, we do have some idea of some important regions in the brain for the affective component of pain.

The similarity of animal and human central nervous systems can, of course, be granted to a significant extent, but there are also many possible or plausible relevant differences:

1 The prefrontal cortex differs enormously between primates, especially humans, and non-primates. ${ }^{11}$ Notably, the prefrontal cortex is thought to be part of the affective pain pathway in humans.

2 The structure and function of the anterior cingulate cortex, insula, and other parts of the affective pathway may differ significantly. To see how plausible this is, bear in mind even just the size: the anterior cingulate cortex in rats is perhaps a few millimetres long at most, and the entire brain lacks gyrification. While the ACC in humans and rats no doubt share some similarities, it is a huge leap to suppose that they share all the relevant similarities.

\footnotetext{
${ }^{9}$ In the words of Jeff McMahan (2002), following Derek Parfit.

${ }^{10}$ Obviously, we know in a limited sense that the brain causes consciousness. But we have no idea how it is that the brain - a bundle of cells firing around electrons and sodium ions - causes consciousness, even if we have some idea of which parts of the brain appear to be particularly important for it.

${ }^{11}$ Fuster (2008).
} 
3 The cell types may differ significantly.

4 Neurotransmitter function may differ significantly.

5 Genetic expression may differ significantly. ${ }^{12}$

6 Brain function on a larger scale may differ significantly (e.g. different system-level patterns, such as different wave patterns, which - as we shall see - may well be significant for conscious experience).

The confident animal pain theorist has to suppose that none of these possible differences contributes significantly to the morally relevant dimensions of pain described. This will require showing far more than just nociception in animal brains: no one denies that. But the morally relevant components (including the generation of qualia in the first place) may depend on one or many of these diverse factors, and at present there simply is not sufficient evidence to say that all the components necessary for morally relevant pain are shared between humans and animals.

We will shortly respond to the most specific neuroanatomical claim that defenders of animal pain make as evidence for their claim - namely, that animals have an anterior cingulate cortex and that this appears to be involved in pain processing. I will demonstrate that the situation is considerably more complicated.

\section{A Controversial Thesis}

It is worth concluding with some hints in the literature of serious discussion about animal pain. It is a regrettable feature of academic discourse that the popularity of a view often renders such a view more palatable, but it is nevertheless a real one. For those who appreciate such epistemic deference, I note several authors who have deliberately or not - taken seriously the question of animal pain, and its similarity to human pain.

Murray discusses the work of Gary Varner, who gives six criteria for determining the similarly of animal pain to human pain: pain behaviour similar to that of humans, effectiveness of pain-killers, presence of endogenous opioids, presence of nociceptors, presence of a central nervous system, and connections between nociceptors and the central nervous system. ${ }^{13}$ While I do not think this is quite yet an adequate account, nevertheless it is clear that even this account might seem to favour the view that a considerable number of animals do not feel pain. In connexion with this, many authors have highlighted the inadequacy of animal models of pain: Campbell and Meyer note that certain ostensible pain behaviours (e.g. autotomy) might have nothing to do with pain-related reasons at all, as well as pointing out that animal models of pain often show little correlation with clinical effectiveness: "Allodynia in painful diabetic neuropathy in humans is infrequent yet appears to be robust in rat models. NK1 antagonists appeared to have promise for treatments of pain based on animal models yet to date have not proven useful in patients." ${ }^{14}$ They point also to Vierck's scepticism ${ }^{15}$ about

\footnotetext{
${ }^{12}$ Hodge et al. (2019) offers a helpful summary of some of these differences between humans and mice.

${ }^{13}$ Varner (1998).

${ }^{14}$ Campbell and Meyer (2006).

${ }^{15}$ Vierck (2006).
} 
animal models, where he argues that reflex measures of pain do not measure pain at all, only testing motor responses.

It is possible that intuitions are particularly incorrigible when discussing emotionally or politically invested matters. One might be helped to see the genuine problem in determining whether animals feel pain by comparison to a similar debate, also with considerable political investment, but where the question of morally relevant kinds of pain is taken very seriously indeed: foetal development. It is a serious matter of inquiry whether foetuses feel pain, and when foetuses or newborns begin to feel pain in a morally relevant sense, despite it appearing intuitively obvious that they do. After all, they display pain behaviour and have grossly similar central nervous systems to adult humans from a reasonably early stage. Why should people denying that foetuses and newborns feel pain be taken seriously, and people who deny that animals feel pain not?

\section{Objections}

\subsection{Ethical Concerns}

A number of authors have responded to Murray, and their arguments merit serious consideration. Some of these are not relevant to this paper since, for example, they are commenting on the theological context of Murray's arguments, or because they respond to Murray's claim that non-hominoid animals do not have a prefrontal cortex, a claim I do not make. But there are a number of salient objections to Murray's scepticism, to which we now turn.

One objection to the thesis I am defending is that it implies there is nothing wrong with torturing animals and that, since torturing animals is clearly immoral, my thesis is false. There is a straightforward sense in which this argument is question-begging. For 'torture' implies feeling morally relevant pain. It is a thick concept. But if animals do not feel pain, then manipulating them in certain ways is not torture at all. The sceptical thesis is therefore compatible with torturing animals being wrong - it just denies that animals can be tortured. So the premise:

1 If animals do not feel pain, then torturing them is morally acceptable.

is equivalent to:

1 If animals do not feel pain, then causing them to feel pain is morally acceptable.

And this premise is clearly either nonsensical or utterly implausible. In order to fix the argument, it must be modified:

1 If animals do not feel pain, then kicking them for fun is morally acceptable.

2 Kicking animals for fun is not morally acceptable.

3 Therefore, animals do feel pain.

But then it is clear how question begging the argument is. For the very reason people give for asserting premise 2 is that animals do feel pain. If there were no evidence 
whatsoever that animals felt pain, people may not hold to premise 2. And this would thereby undermine the support for the conclusion. Premise 2 is not arrived at by a priori moral reflection. It is, for most people, based on the fact that animals feel pain. But in that case, the argument is clearly circular. So this is not an objection to my thesis.

Of course, there may be reasons for not kicking animals even if animals do not feel morally relevant pain, as we will now see. Faith Pawl gives a more plausible argument along these lines:

'If neo-Cartesianism is true and the neo-Cartesian grounds an animal's moral standing solely in its creaturehood and ecological function, I can see no reason why the neo-Cartesian ought to treat pigs any differently than petunias, since neither can suffer. Trampling an animal is no different from trampling a patch of wildflowers.' 16

Pawl may be right here. The argument may be successful for confident neo-Cartesians - at least, confident neo-Cartesians could not think mistreating animals is wrong insofar as that mistreatment consists only in forcing the animal to feel pain. But are there reasons to avoid mistreatment that do not appeal to actual subjective suffering on the part of the animal?

The most immediate thought that comes to many is a Kantian kind of worry: that abusing animals likely perverts one's attitudes towards genuine moral agents, or that torturing animals necessarily comes from enjoying cruelty. But Pawl may be right to search for an animal-centred reason - one that reflects the inherent value that most of us take animals to have.

I think such a reason can be given. Most of us would agree that there are kinds of mistreatment that do not involve any negative experiences. Let us call these 'painless harms'. ${ }^{17}$ Some of the paradigmatic cases of painless harms seem to be cases of disrespect, desecration, indignity, or however else one prefers to characterise it. ${ }^{18}$ When humans are disrespected, this is a serious wrong, even if they do not suffer - for example, when a lover is betrayed without ever finding out.

Can only humans be disrespected? Perhaps, but this is not obvious. Many people believe that all living beings (and perhaps many non-living beings) have intrinsic value (indeed, this appears to be part of the Thomistic account Pawl offers), and hence ought to be respected in certain ways. It is at least plausible - and that is all the neo-Cartesian needs - that certain parts of the natural world require respect even in the inability to experience suffering, and that this mandates certain treatment.

Pawl would rightly respond that painless harms can be suffered by plants as well, and hence the parity re-emerges. But this parity can look very different for animals and plants, since what it means for an animal's life to go badly is very different from what it means for a plant's life to go badly.

Likewise, what it means to respect or steward something differs depending on what the thing is, as (plausibly) does the seriousness or severity of disrespecting it.

\footnotetext{
${ }^{16}$ Pawl (2014).

${ }^{17}$ Pawl says that an animal suffers when 'it experiences its life as going badly, and an animal's life goes badly when its central desires are frustrated, its flourishing is diminished, or both.' My 'painless harms' refer to an animal's life going badly without the animal having an experience of this.

${ }^{18}$ See Haidt (2012) for a helpful account of this 'pillar' of morality.
} 
Respecting the oldest tree in the world is very different to respecting a human child. It requires completely different norms (though sharing some in common), and failure to respect those norms is plausibly much more serious in the case of the human child. If so, animals could plausibly occupy a middle ground: they are owed respect, much like petunias, but this respect generates very different norms to the norms for respecting petunias, and violation of those norms is plausibly more serious, even in the absence of the ability of either to suffer. Hence, there is a plausible account of animal value and our duty not to mistreat them, that does not depend on ability to suffer and yet allows for a significant disparity between animals and plants.

Regardless of whether this approach succeeds or not, the objection does not appear to have any weight against the scepticism I am defending. For those who are confident that animals do not suffer, the objection may have weight. But for those who are simply sceptical of the quality of the standard reasons offered, there is a perfectly good animalcentred reason not to hurt them: in case they do suffer. It may still seem plausible or probable to us - for reasons we may not be able to articulate or describe - that animals feel pain.

Even in the absence of a powerful argument to the conclusion that animals feel pain, there is still a moderate chance that animals do, in fact, feel pain. In the same way that it would be imprudent to an immoral degree to detonate a building knowing that there was a moderate chance somebody was inside, so it would be an immoral kind of imprudence that would allow the torturing of animals. This is not, therefore, an objection that weighs significantly against the scepticism I am defending.

\subsection{Pain Behaviour Revisited}

Perhaps the most forceful replies have come from a number of authors seeking to bolster the argument from pain behaviour by suggesting more careful statements of the evidence. Let's review some of these. ${ }^{19}$

Pawl describes some pain behaviour in more detail, showing that the pain animals experience may extend to emotional pain, rather than just physical pain. She gives the examples of PTSD-type symptoms in orphaned elephants and the stress/anxiety-type responses of baboons in their frequent distressing social situations. ${ }^{20}$

A number of authors then point to more specific observations regarding pain behaviour than the mere fact they exhibit it:

1 Animals exhibit clearly non-reflexive pain behaviour such as guarding, grooming, and learning to avoid a source of pain. (Francescotti, Engel ${ }^{21}$ )

2 Animals seek painkillers - for example, arthritic rats drink fentanyl in preference to a sweet solution they would ordinarily prefer. (Francescotti)

3 Animals exhibit decreased pain behaviour after taking analgesia - for example, rainbow trout limit certain possible pain behaviours (such as rubbing the affected

\footnotetext{
${ }^{19}$ Halper and Halper (2014) give statements of the evidence largely overlapping with the material presented here.

${ }^{20}$ Sollereder alludes to similar evidence.

${ }^{21}$ Engel Jr. (2009).
} 
body part against the side of the tank) after morphine administration. (Francescotti, Engel)

4 Surgically deafferented animals display self-destructive tendencies. (Engel)

5 Animals have the same separate discriminatory/affective pain processing pathways that humans have - for example, rats ordinarily prefer the dark, but spend more time in the light when their paws are made hypersensitive and given painful stimuli in the dark area of an environment. But rats with anterior cingulate cortex lesions i.e., those who might be expected to have pain asymbolia - went back to the dark side, apparently mindless of the painful stimuli. (Pawl)

What can we say about these cases? Could the neo-Cartesian explain this evidence?

It seems so, but it is worth offering a clarification first. The neo-Cartesian does not claim that all pain behaviour in animals is reflexive in the sense that spinal cord reflexes are. The neo-Cartesian can agree (and likely will agree) that some pain behaviour involves much 'higher' CNS mechanisms. They can even agree that these mechanisms may be conscious in some cases - they just deny that it necessarily involves a morally relevant aversive reaction to pain.

Likewise, let us be clear that the neo-Cartesian is fully committed to nociception even quite sophisticated nociceptive systems. While the neo-Cartesian is very sceptical about morally relevant pain, they are not at all sceptical about nociception. Nociception is extremely important biologically, and often very complex. So in general, we should not be surprised by nociception and its anatomical substrates, even in the cortex.

Given this, the other suggested kinds of pain behaviour are not difficult to explain at all, for the reasons already given in the above section on pain behaviour. Paininduced behavioural responses also often aid survival and reproduction: nursing a wound will help me survive and reproduce, just as a flexor response to a noxious stimulus will help me survive and reproduce. Neo-Cartesians have never claimed that all animal responses to pain must be reflexive in the sense that spinal reflexes are. It does not make any difference to the form of the neo-Cartesian explanation the level at which the responses to pain occur, or their sophistication. What matters is: would we expect the pain behaviour, given evolution? Whether spinal or cerebral, the answer is: 'yes'. This includes more sophisticated pain behaviour such as learning.

The second objection can be handled similarly, just by thinking of analgesia-seeking as a kind of pain behaviour. But perhaps there is a deeper objection here: we would expect evolution to select for behaviour that avoids noxious stimuli and promotes healing, but would we expect evolution to select for behaviour which merely provides symptomatic relief?

I think, again, the answer is yes. Pain is an alert system: it suggests that something is wrong. Sometimes it misfires: things are painful even when they are not noxious, and things can relieve pain without actually healing. What we are asking animals to do is discriminate carefully between these: to examine the cases of pain related to a genuinely harmful stimulus and distinguish them from cases of pain unrelated to a genuinely harmful stimulus. Likewise, we are asking them to distinguish between genuinely healing methods of analgesia and purely symptomatic methods of analgesia. It is not implausible to suppose that animals, in general, cannot do so or have insufficient 
interest in doing so. ${ }^{22}$ If so, the 'thought' process of an animal (insofar as it could be called this) would be: pain and harm are tightly correlated. Hence, if I am in pain, I am probably being harmed. And that which reduces my pain probably is helping to reduce that harm. And hence the animal would be expected to take analgesia. To expect that an animal has sufficient knowledge of medicine to realise that fentanyl is not actually helping it survive may be expecting too much.

This, in turn, explains the decrease in pain behaviour after administration of analgesia. ${ }^{23}$ It is perfectly plausible that an animal would 'think' that since it is no longer in pain, it no longer requires pain behaviours. And if fentanyl is the easiest way to a 'cure', then an animal would be expected to take that route. ${ }^{24}$

Engel notes the self-destructive tendencies displayed by animals that have been surgically deafferented, arguing that this constitutes compelling evidence that feeling pain enhances survival value. But this is entirely consistent with the sceptical thesis. Nociceptive signals in afferent neurons do indeed enhance survival value - and this is true regardless of whether animals feel pain or not. Indeed, it is the reason we would expect pain behaviour regardless, and so is the reason much of the evidence for animal pain is undercut.

Finally, then, the neo-Cartesian can agree - and should even think it likely - that pain in animals has at least two elements: discriminatory and something like affective. Indeed, it is hard to see how animals could effectively respond to pain without both. Any animal using nociception needs to know not only where a stimulus is, but that it is distinct from ordinary somatosensory stimulation. Hence, any effective nociceptive system must have these two sensory aspects, and neither are remotely surprising. NeoCartesians would never want to say that animals do not even have an analogue of the affective modality: they just think that this affective component is more attenuated than in humans and may not involve genuine suffering.

Is it surprising that they are relayed in separate anatomical pathways? Well, firstly, it's not entirely clear how separate they are: there is mounting evidence that somatosensory cortex is now implicated in the affective pathway, ${ }^{25}$ and Ong et al. (2019) notes that the anterior cingulate cortex (ACC) is implicated in both functions. But even if they were totally separate, this would not be surprising either: at least, no more surprising than given the theory that animals do feel morally relevant pain. It's not clear on either theory why the pathways separate out so distantly in their anatomy: and it is perfectly plausible that when we do find out, the reason could apply equally to an attenuated affective response.

You might come away from all of this thinking how bizarre this causal explanation sounds. That isn't a clear criticism, but in any case, there is another very good reason

\footnotetext{
${ }^{22}$ Or perhaps they do have some negative feeling related to pain which they would prefer to get rid of possible, but which does not constitute morally significant suffering - perhaps in the way that having an unread e-mail is 'annoying' to many of us, leading us to make efforts to open it, but the omission of which does not cause significant suffering.

${ }^{23}$ Ignoring worries we have seen concerning whether pain behaviour really is such, and regarding the varying efficacy of analgesics between animals and humans.

${ }^{24} \mathrm{An}$ anonymous reviewer adds the suggestion that there are other possible explanations for analgesiaseeking: perhaps they even cause euphoria in some animals, for example. This is possible - even in humans clinical practice, we see that opioid analgesics have various effects on mood and cognition - but it is not a central pillar of my argument. Thanks to the reviewer for this suggestion.

${ }^{25}$ See e.g., Feinstein et al. (2016).
} 
why it should not seem bizarre to many people: many people do, in fact, tell this exact causal story. I won't go into a comprehensive exploration of the philosophy of mind here, but it is fair to say that a considerable number of philosophers - perhaps most deny that mental phenomena cause physical phenomena. You could think of the causal story I am telling this way: suppose epiphenomenalism is true. Then just cut out the epiphenomena (which are causally ineffacious in any case, and so make no difference to the causal story), and you are left with the neo-Cartesian explanation. At least for these philosophers, it should not only be plausible or conceivable that the alternative causal story I'm suggesting is true: that is exactly the causal story they are already committed to. For these philosophers, then, it seems clear that no conscious phenomena are required to explain pain behaviour.

\subsection{Anatomical disparities.}

It is surprising that not many authors have followed up in detail on the anatomical arguments, since to my mind they are by quite some way the best candidates for an argument that animals feel pain, at least in theory. A few writers comment exceedingly briefly on the similarities, ${ }^{26}$ and as we have seen, Faith Pawl draws attention to the different affective and sensory pathways seemingly demonstrated in rats as well as humans.

Some have criticised Murray for denying that animals other than humanoid primates have a prefrontal cortex, ${ }^{27}$ which on the straightforward reading is indeed false. Murray has defended his remarks here by drawing attention to the differing demarcations for prefrontal cortex in the literature. ${ }^{28}$ I have no interest in adjudicating in this debate here, as my argument is independent of whether other animals have a prefrontal cortex.

Here is one version of Murray's argument that I think is too strong:

1 Without a certain part of the brain (for example, anterior cingulate cortex), animals/ humans have pain asymbolia.

2 Animals probably lack this part of the brain.

3 Hence, animals probably have pain asymbolia.

To be clear: I don't think this argument works. I don't think we know enough about the brain to make these claims yet (though we may in future), but it is precisely that lack of knowledge that I think should point us towards uncertainty in the interim.

Murray does seem to think something like this argument can work. For example, he claims:

'these cases confirm that in human beings the 'affective' pathway terminates in the prefrontal cortex, a region of the mammalian brain which was the last to evolve (and so occurs only in humanoid primates). Thus, the evidence available to us would tend to indicate that the affective side of pain is not experienced by organisms other than humans and other humanoid primates."29

\footnotetext{
${ }^{26}$ E.g., Engel and Francescotti.

${ }^{27}$ E.g., Sollereder.

${ }^{28}$ Murray (2014).

${ }^{29}$ Murray (2008), 68.
} 
It may well be that the terminal points of the affective pathway are demonstrably nonexistent in most mammals. I think we are probably some way from showing that. Either way, I do not think we need to show this for agnosticism to be justified.

There are a few reasons I think we should be sceptical about Murray's apparent argument:

1 Convergent evolution often provides the same function through different mechanisms: even if animals do not have the same affective mechanisms that humans have, they may have an alternate mechanism.

2 Reports of lobotomies and lesions often do not contain enough specific information about which areas of the brain have been removed: 'lobotomy' is somewhat vague, but the precise areas removed make a big difference to their interpretation. ${ }^{30}$ The reason is that the anterior cingulate cortex, for example, extends far down the phylogenetic chain: if the anterior cingulate cortex is the relevant part the removal of which causes pain asymbolia, then since rats have anterior cingulate cortex (the removal of which decreases pain behaviour), it is plausible that rats have pain like humans (though not guaranteed, as we will see).

3 We also know that small changes in this region may make a big difference, and the contributions are not straightforward. Sollereder points out that some patients with lobotomies had worse pain, while others had pain asymbolia initially before 'relearning' the suffering. Fuchs et al. (2014) notes that many cingulotomy patients did not have improved pain, and that activation of the ACC can sometimes reduce pain. He also notes that the ACC appears to be related to some types of pain more than others. Feinstein et al. (2016) notes that cingulotomy can cause increased pain. He also describes a case of complete destruction of the ACC associated with hyperpathic responses to pain, and notes that psychopaths have increased insula activity when observing pain in others (the insula being a closely related part of the affective pathway, activation of which is normally associated with pain).

4 As Sollereder also points out, patients with pain asymbolia generally significantly limit their pain behaviour. If so, then we might expect animals who effectively have pain asymbolia to have limited pain behaviour - but they don't. ${ }^{31}$

So we have good reason not to be confident, on the basis of anatomical arguments, that animals have something like pain asymbolia. But, I now suggest, many of these same considerations also advise caution in the other direction as well. Specifically, the complexities of nociception and pain give us reason to doubt that the similarities between humans and animals are that clear.

The most promising argument for animal suffering from neuroanatomy is probably something like:

1 The anterior cingulate cortex is where the affective element of pain is represented in humans.

\footnotetext{
${ }^{30}$ Feinstein et al. (2016) points out that the lesion studies often involve lesions far more extensive than the standard 'pain matrix'.

${ }^{31}$ One might respond to Sollereder by suggesting that the pain behaviour would be achieved by another means through convergent evolution.
} 
2 Many other animals, including rats, have an anterior cingulate cortex.

3 Those animals also show an affective cingulate cortex which contributes to nociception: lesions of the ACC lead to diminished pain behaviour.

4 Hence (and perhaps for other reasons), it is likely that animals likely have the same discriminatory/affective separate nociception pathways, and that their affective pathway, culminating in the ACC, performs the same job as in humans, and hence delivers morally relevant pain.

Perhaps this is not how the pain theorist would present the argument; Murray's critics have not presented a clearer argument from anatomy, to my knowledge.

This argument is not persuasive, for a variety of reasons.

Firstly, note that for 4) to follow from the premises, the anterior cingulate cortex has to be sufficient for pain. That it is necessary is not enough: nociceptors (and blood flow to the brain) are also necessary for certain kinds of pain, but the fact that both humans and rats have nociceptors is not a persuasive argument for rats feeling morally relevant pain.

This is complicated by the difficult in determining the precise neural correlates of consciousness in general and for pain. For in the strict sense, it is not clear that activity in a brain region could be necessary or sufficient for phenomenon $\mathrm{x}$. It may not be necessary for $\mathrm{x}$ because there is always the possibility (perhaps from convergent evolution) that another structure could cause $\mathrm{x}$ in its place. It may not be sufficient for $\mathrm{x}$ because even if activity in that region would ordinarily generate conscious pain, there may be some other inhibitory factor preventing that phenomenon from occurring. When we talk of ACC activity being necessary for pain, we mean at most that it is necessary in the absence of any alternate mechanism, and that we know of no alternate mechanism. When we talk of ACC activity being sufficient for pain, we mean at most that ACC activity causes pain given the ordinary operation of the rest of the brain. This latter clause shows that even if the ACC is sufficient for pain in humans, however, it may not be in animals - because the ordinary operation of the rest of their brain is different (for reasons described in 'Anatomical arguments' above).

The situation is further complicated by the fact that we have no idea how conscious phenomena are generated in general - that is, how they relate to their neural substrates. Neural activity does not seem to suffice for consciousness - our enteric nervous system and cerebellum are extremely complicated neural systems but do not seem to be conscious. Koch offers an overview ${ }^{32}$ where he considers various theories for the neural correlates of consciousness both in general and for specific phenomena. What does seem clear is that we are far from being able to claim that some neural situation is sufficient for a certain conscious experience. Indeed, it might be that conscious experiences do not arise from simple activity of a particular brain region at all, but that they emerge from far more complicated and widely distributed patterns not detectable by gross anatomy. ${ }^{33}$

\footnotetext{
${ }^{32}$ Koch (2016).

${ }^{33}$ Koch (2016). Ong et al. (2019) also offers a brief discussion of oscillations in the prefrontal cortex as biomarkers for pain, for example. This general suggestion is compatible with there being some gross areas activity within which is partly responsible for, or ordinarily correlated with, certain conscious experiences.
} 
Even if stimulation of the ACC in humans gave, with reasonable frequency, a sensation of pain, that would not show that ACC activity is sufficient for suffering. It might be, for example, that the ACC only produces conscious pain of a certain kind because of other brain structures or physiology with which ACC activity interacts, or even because of other structures or physiology within the ACC itself but unique to higher mammals. That is, we have no clear evidence that the ACC is the 'final step' which is, on its own, sufficient for conscious affect. We have at best evidence that it is necessary - though I shall argue we do not even have that. Other factors that may also be needed could include not only other parts of the brain responsible for the basic sensation of pain, but also the parts of the brain I described under 'Anatomical arguments' earlier - for all we know, these other parts are responsible for the morally relevant requirements of pain I have described.

In short, for the argument to persuade us, we need to show that ACC activity is sufficient for conscious pain in animals. For the various reasons I have described, we simply do not have evidence that the ACC is sufficient for conscious pain even in humans.

Secondly, the situation is worse, because we actually have evidence to the contrary. The anterior cingulate cortex appears to be neither necessary nor sufficient for pain, even in the limited senses I described above. I have already outlined some of the evidence showing that the relationship between the ACC and pain is far more complicated than often suggested. ${ }^{34}$ But we can go further: that the ACC is not necessary has been demonstrated by a case in which patient had a preserved affective response to pain despite almost total bilateral destruction of not only the anterior cingulate cortex, but also the insula and amygdala, also key components of the affective pathway. ${ }^{35}$ Indeed, the patient had excessive responses to pain beyond the norm.

What is more important, however, is that the evidence suggests the ACC is not sufficient for pain. Perhaps the most impressive evidence for this comes from a study demonstrating the exact same activation of the 'pain matrix' (including the ACC) in patients with congenital insensitivity to pain. These patients feel no (physical) pain and yet showed the same pattern of activity in the ACC and related structures on subjection to painful stimuli. ${ }^{36}$ The authors also note that patients with CIP have shown ACC activation when observing pain in others.

Moreover, some studies have shown that stimulation of the ACC can reduce pain behaviour in animals. ${ }^{37}$ While there are plausible explanations for this that are consistent with the ACC generally giving rise to painful experiences, what it shows is that it is not a simple case of anterior cingulate cortex activity equating to conscious pain. Different parts of the anterior cingulate cortex have different functions, and some of these distinctions may differ between humans and animals.

It seems true that, ordinarily, ACC activation facilitates conscious pain (though sometimes it reduces pain), in both humans and animals. But it appears very unlikely that it is sufficient (in the relevant sense) for pain, and hence the fact that rats have an

\footnotetext{
$\overline{34}$ See the above discussion where I cite examples from Sollereder, Fuchs and Feinstein.

${ }^{35}$ Feinstein et al. (2016).

${ }^{36}$ Salomons et al. (2016). It is possible that the activation of the ACC before conscious experience of pain suggests that the ACC is not the final neural substrate, but I have not seen much commentary on this point from professional neuroscientists. See Ong et al. (2019) and Fuchs et al. (2014).

${ }^{37}$ Fuchs et al. (2014).
} 
anterior cingulate cortex which contributes to nociception does not show that they feel morally relevant pain. Remember that the neo-Cartesian story is that non-reflexive nociception is common throughout the animal world, but that extra factors are needed to make this nociception morally relevant.

So the ACC is not sufficient for pain in humans. But the complexity of the ACC and the likely differences between animal and human ACCs suggest we have even less reason to think that ACC activation is sufficient for morally relevant pain in rats and dogs. Rats and dogs may share most of the same gross structures in the brain with humans, but that is very far from their sharing the same detailed features, and for all we know these detailed features are necessary for morally relevant pain. ${ }^{38}$

Given how complex the role of the ACC in nociception is, the fact that rats and dogs have an ACC which plays a role in nociception simply does not suffice for the analogy required to make an argument from neuroanatomy persuasive. Suppose, for example, that in the case of bilaterally destroyed ACCs, the $1 \%$ of the ACC preserved happened to be responsible for the affective component of pain. What guarantee do we have that the ACC of a rat is relevantly similar to that part? Very little, I suggest. And so given our lack of knowledge regarding how, exactly, the ACC relates to morally relevant pain, given the likely complexity of that relationship, and given the likely reliance on other areas or features of the brain for which we have not established parity between rats and humans, the argument from anatomical similarities simply is not sufficiently developed to justify attributing morally relevant pain to animals. ${ }^{39}$

To make things a bit clearer, here is a story that seems perfectly consistent with the simplified account of the data I have presented: ACC activity is an important step in the nociception pathway. ACC activity in turn (or in conjunction with some other factorwhether simple brain activity in another area, or a particular waveform, or a particular cell type activity, for example) causes some other event elsewhere in the prefrontal cortex (or maybe even elsewhere in the ACC), which is the actual neural correlate of morally relevant pain. Cutting out the ACC normally causes asymbolia because it takes out an important part in the normal pathway. And stimulating the ACC is normally enough to cause morally relevant pain not because it is the neural correlate of morally relevant pain, but because it causes another event which is the correlate of morally relevant pain.

Rats work by and large the same, and so ACC activity is normally associated with nociception. However, in rats, the ACC does not have the same connections to the PFC, or lacks the same cell types in a certain region of the ACC, or for whatever reason, does not have the additional factor needed for morally relevant pain.

I am not saying this theory is true - it is sheer speculation - but something like it is entirely plausible. We simply do not know enough about the relevant neuroanatomy, nor about the neural correlates of consciousness, to know even in humans what the final common pathway of morally relevant pain is. Even less so in rats and dogs.

Engel suggests some other anatomical or physiological considerations which are worth briefly responding to. He asks why organisms incapable of feeling pain would

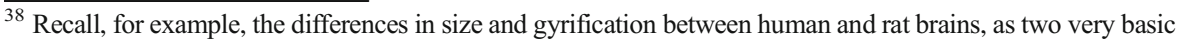
examples.

${ }^{39}$ With the possible exception of some primates. My concern in this article is with the large majority of mammals. Discussion of whether primates closely related to humans feel pain is beyond the scope of this paper.
} 
have endogenous pain-control systems. There are multiple obvious answers. The first is that evolution throws up all sorts of things by chance - they are often only removed if there is a negative selection pressure against them. So it might be that there is no teleological purpose at all. The second is that evolution produces many systems which are non-specific. It might be that opioids and serotonin have many functions (indeed, they do) and that they also happen to be expressed in pain centres in the central nervous system. Indeed, serotonin in particular is known to be involved in the projections of the raphe nuclei - a famously non-specific system spreading serotonin to almost every area of the brain. It is not implausible that some of these projections do not have any obvious use.

The third, and most plausible option, is that pain control systems reduce the salience of nociceptive signals in the central nervous system - signals which would cause excessive, deleterious responses to pain if they were not suppressed. This gives a very plausible evolutionary reason for endogenous pain control systems.

Even if animals do feel pain, however, the purpose of these endogenous systems is not trivially easy to discern, so the agnosticism here should not count as a mark against the sceptical thesis. We do not know for certain why endogenous pain control systems exist regardless of whether or not animals feel pain - and so this cannot favour one theory over the other. Positing conscious morally relevant pain does no work in demystifying it.

Engel refers also to the fact that animals have efferent and afferent nerves running throughout their bodies. But the same could be said of a simple, unconscious reflex arc, such as the flexor withdrawal response found in humans. So this hardly constitutes strong evidence that animals feel pain.

\subsection{Other objections}

While there have been a number of other responses to Murray, a detailed discussion of them lies beyond the scope of this paper. A few brief comments are in order.

Pawl objects that scepticism about animal pain seems viciously close to radical scepticism. Likewise, Dougherty suggests that we take common sense as our starting point, and argues that the data we have do not serve as defeaters for our common-sense starting position.

I hope to have shown that these are over-stated: there are fair reasons that can be adduced in favour of scepticism. But perhaps more germanely, my fundamental thesis is not really affected by this objection. I think it is perfectly plausible that animals feel pain - indeed, for my own part, I think it is likely - I just think that the evidence people ordinarily cite is not very impressive evidence, and that withholding belief could also be a justifiable position.

Dougherty and Francescotti also aim to lower the complexity of neural machinery needed for morally relevant pain by identifying other kinds of pain which do not require such advanced apparatus, and by arguing that higher order cognition may not be necessary for morally relevant pain. Again, this is entirely consistent with my argument. Maybe animals do feel morally relevant pain (I am inclined to think they do). Positing a lower threshold for the neural complexity required for morally relevant pain certainly makes it more likely that animals feel morally relevant pain. But it still does not constitute firm evidence that they do, and it still seems clear that something beyond 
basic nociception is needed. Until we have firm evidence that animals have those extra factors, my argument remains unimpeached.

\section{Implications}

We have already seen an implication our scepticism does not have: it does not mean we have licence to be cruel to animals. But what implications does it have? Since my main thesis is to argue for animal pain scepticism, I will not draw these out in great detail. I offer them only as exercises for future research.

Firstly, it shows that certain reasons for not being cruel to animals plausibly carry considerable weight. In particular, moral caution seems like a weighty principle. If we have significant doubt over whether an action seriously harms another morally considerable being, we should refrain from that action. This will be of relevance to the moral caution literature more generally, but also, perhaps, has relevance in parallel debates. Perhaps the foremost researcher on foetal pain in the world has recently made the case that foetuses feel pain from as early as 12 weeks, ${ }^{40}$ for example (and some writers ${ }^{41}$ think that foetuses might well feel pain even earlier). Many, perhaps most, of the arguments used in support of animal pain are equally weighty in support of foetal pain. If so, we have considerable reason to withhold from procedures which would cause intense pain to the foetus, or at least mandate analgesia. Likewise, other controverted rights might be granted in the absence of compelling arguments to the contrary. Hence, for example, moral caution arguments have been offered against abortion. ${ }^{42}$ If moral caution is a significant reason to withhold from causing animals (ostensible) significant pain, moral caution must have a significant place in ethics more widely.

Likewise, the principle of respect may carry considerable weight. If abusing dogs is wrong because it disrespects them even in the absence of pain, this may elucidate some of our obligations to other parts of the natural world which do not, or may not, feel pain, such as the environment, or foetuses.

Secondly, this conclusion might point towards a greater role for emotion in moral reasoning. Our initial reaction to seeing animals suffer is not to judge dispassionately that they are in pain and that this should motivate us to help them. Our initial reaction is to sympathise. And in this case, if we believe that animals do indeed feel morally significant pain, we should be inclined to think that our basic moral instincts are more in line with the truth than our philosophical reflection. Of course, this will not be foolproof: some moral emotions are clearly wrong! But if they are right here, and if philosophical reflection is inconclusive, we should at least be respectful towards the role of emotion in moral reasoning.

Relatedly, this case shows the substantive assumptions necessary to ground a naïve realist picture of the world. Our ontological commitments simply go considerably beyond what we can defend evidentially. Of course, in a sense this is not news: philosophers have wrestled with the threat of scepticism for centuries. But the difficulty presented here may reasonably be thought to exacerbate any problem of scepticism, and

\footnotetext{
${ }^{40}$ Derbyshire and Bockmann (2020).

${ }^{41}$ E.g., Howsepian (2011).

${ }^{42}$ E.g., Moller (2011).
} 
could perhaps support theses built on the problem of scepticism (e.g. ostensible solutions). Likewise, any basic epistemic principles responding to various sceptical problems should be assessed, in part, on whether they help respond to the problem I have presented here.

\section{Conclusion}

In sum, there is significant reason to doubt the common sense view that animals feel pain in a morally relevant sense. The reasons commonly offered in support of the view are unpersuasive, and it is clear that a comprehensive account of morally relevant pain allows for significant disagreement over whether animals are victims of such. There is substantial room for empirical confirmation of one view or the other, and we should wait to see the results of such investigation before investing too much confidence in intuition. Even those who - like myself - remain convinced that animals do feel morally relevant pain are presented with powerful reasons for humility in that view.

Open Access This article is licensed under a Creative Commons Attribution 4.0 International License, which permits use, sharing, adaptation, distribution and reproduction in any medium or format, as long as you give appropriate credit to the original author(s) and the source, provide a link to the Creative Commons licence, and indicate if changes were made. The images or other third party material in this article are included in the article's Creative Commons licence, unless indicated otherwise in a credit line to the material. If material is not included in the article's Creative Commons licence and your intended use is not permitted by statutory regulation or exceeds the permitted use, you will need to obtain permission directly from the copyright holder. To view a copy of this licence, visit http://creativecommons.org/licenses/by/4.0/.

\section{References}

Campbell, J., \& Meyer, R. (2006). Mechanisms of neuropathic pain. Neuron, 52(1), 77-92.

Derbyshire, S. W. G., \& Bockmann, J. C. (2020). Reconsidering fetal pain. Journal of Medical Ethics, 46, 36.

Engel Jr., M. (2009). Nature red in tooth and claw: Theism and the problem of animal suffering. Notre Dame Philosophical Reviews, 2009(02), 33.

Feinstein, J. S., Khalsa, S. S., Salomons, T. V., Prkachin, K. M., Frey-Law, L. A., Lee, J. E., Tranel, D., \& Rudrauf, D. (2016). Preserved emotional awareness of pain in a patient with extensive bilateral damage to the insula, anterior cingulate, and amygdala. Brain Structure \& Function, 221, 1499-1511.

Francescotti, R. (2013). The problem of animal pain and suffering. In D. Howard-Snyder \& D. P. McBrayer (Eds.), The Blackwell companion to the problem of evil. Oxford: John Wiley \& Sons.

Fuchs, P., et al. (2014). The anterior cingulate cortex and pain processing. Frontiers in Integrative Neuroscience, 8(35), 1-10.

Fuster, J. (2008). The Prefrontal Cortex (4th ed.). London: Elsevier ch. 2.

Grau, J., \& Joynes, R. (2001). Pavlovian and instrumental conditioning within the spinal cord: Methodological issues. In M. Patterson \& J. Grau (Eds.), Spinal cord plasticity: Alterations in reflex function. Boston: Kluwer.

Haidt, J. (2012). The righteous mind. London: Penguin.

Halper, P. and Halper, M. (2014). "William lane Craig and Michael Murray on animal pain", accessed at http://stephenlaw.blogspot.com/2014/03/post-by-phil-and-monica-halper-re.html on 27/6/20.

Hodge, R. D., Bakken, T. E., Miller, J. A., Smith, K. A., Barkan, E. R., Graybuck, L. T., Close, J. L., Long, B., Johansen, N., Penn, O., Yao, Z., Eggermont, J., Höllt, T., Levi, B. P., Shehata, S. I., Aevermann, B., Beller, A., Bertagnolli, D., Brouner, K., Casper, T., Cobbs, C., Dalley, R., Dee, N., Ding, S. L., Ellenbogen, R. G., Fong, O., Garren, E., Goldy, J., Gwinn, R. P., Hirschstein, D., Keene, C. D., 
Keshk, M., Ko, A. L., Lathia, K., Mahfouz, A., Maltzer, Z., McGraw, M., Nguyen, T. N., Nyhus, J., Ojemann, J. G., Oldre, A., Parry, S., Reynolds, S., Rimorin, C., Shapovalova, N. V., Somasundaram, S., Szafer, A., Thomsen, E. R., Tieu, M., Quon, G., Scheuermann, R. H., Yuste, R., Sunkin, S. M., Lelieveldt, B., Feng, D., Ng, L., Bernard, A., Hawrylycz, M., Phillips, J. W., Tasic, B., Zeng, H., Jones, A. R., Koch, C., \& Lein, E. S. (2019). Conserved cell types with divergent features in human versus mouse cortex. Nature, 573, 61-68.

Howsepian, A. A. (2011). Fetal pains and fetal brains. In S. Napier (Ed.), Persons, moral worth, and embryos (pp. 187-210). Dordrect: Springer.

Koch, C. (2016). Neural correlates of consciousness: Progress and problems. Nature Reviews Neuroscience, 17(5), 307-321.

Libet, B. (1993). The neural time factor in conscious and unconscious events. In G. Block \& J. Marsh (Eds.), Experimental and Theoretical Studies of Consciousness (CIBA Foundation symposium 174). New York: John Wiley \& Sons.

McMahan, J. (2002). The ethics of killing: Problems at the margins of life. Oxford: Oxford University Press.

Moller, D. (2011). Abortion and moral risk. Philosophy, 86(3), 425-443.

Murray, M. (2008). Nature red in tooth and claw: Theism and the problem of animal suffering. Oxford: Oxford University Press.

Murray, M. (2014). “Animal pain re-visited”, accessed at https:/www.reasonablefaith.org/writings/questionanswer/animal-pain-re-visited/ on 27/6/20.

Ong, W., et al. (2019). Role of the prefrontal cortex in pain processing. Molecular Neurobiology, 56(2), 11371166.

Pawl, F. (2014). "The problem of evil and animal suffering: A case study." Doctoral dissertation, St Louis: Saint Louis University.

Ramachandran, V. S. (2006). Lecture at "beyond belief: Science, reason, Religion \& Survival” conference. La Jolla: Salk institute.

Salomons, T., et al. (2016). The 'pain matrix' in pain-free individuals. JAMA Neurology, 73(6), 755-756.

Sollereder, B. (2016). When humans are not unique: Perspectives on suffering and redemption. Expository Times, 127(6), 269-276.

Varner, G. (1998). In Nature's interests? Interests, animal rights, and environmental ethics. Oxford: Oxford University Press.

Vierck, C. (2006). Animal studies of pain: Lessons for drug development. In J. Campbell, A. Basbaum, A. Dray, R. Dubner, R. Dworkin, \& C. Sang (Eds.), Emerging strategies for the treatment of neuropathic pain. Seattle: IASP Press.

Publisher's Note Springer Nature remains neutral with regard to jurisdictional claims in published maps and institutional affiliations. 